Viso - Cadernos de estética aplicada Revista eletrônica de estética

ISSN 1981-4062

No 11, jan-jun/2012

http://www.revistaviso.com.br/

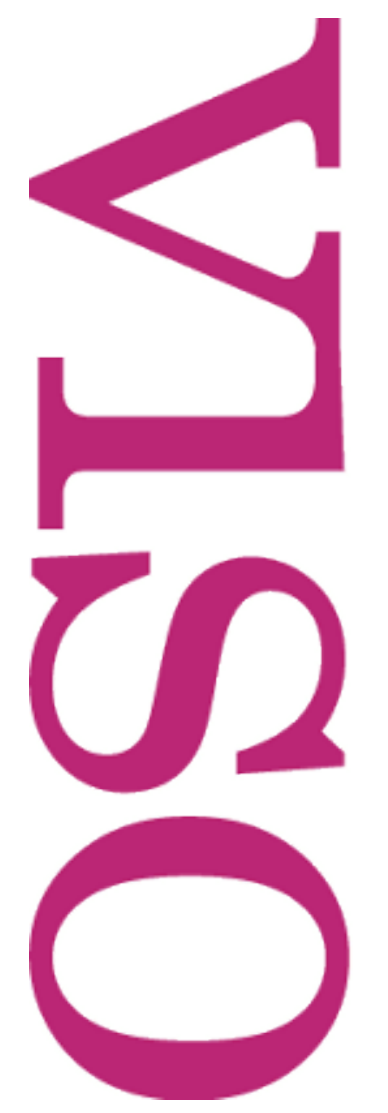

\title{
Corações a nu: coragem da verdade, arte moderna e cinismo em Baudelaire, segundo Foucault \\ Ernani Chaves
}




\section{RESUMO}

Corações a nu: coragem da verdade, arte moderna e cinismo em Baudelaire, segundo Foucault

No seu último curso ministrado no Collège de France, A coragem da verdade (1984), Foucault afirma que o cinismo antigo é a expressão maior da "parrêsia", do "franco falar". Esta característica reaparece em pelo menos três momentos históricos posteriores: no ascetismo cristão medieval, no revolucionário dos séculos XVII e XVIII, assim como na figura do artista moderno, própria ao século XIX. O objetivo deste artigo é então o de tentar compreender a referência a Baudelaire entre esses artistas modernos, que constituem esse retorno do cinismo. Para isso, procuramos mostrar em que medida a aproximação de Baudelaire implicou, para Foucault, seu afastamento em relação a Sade.

Palavras-chave: verdade - cinismo - modernidade - arte

\section{ABSTRACT}

Mon coeur mis a nu: the courage of truth, modern art and cynicism in Baudelaire, according to Foucault

In his last course ministered at the Collège de France, The courage of truth (1984), Foucault asserts that antique Cynicism is the biggest expression of "parrhesia", of the "frank spoken". This characteristic reappears in at least three posterior historical moments: in the medieval Christian asceticism, in the revolutionary of the seventeenth and eighteenth centuries, as well as in the figure of the modern artist, peculiar to the nineteenth century. Therefore, the aim of this paper is to attempt understand the reference to Baudelaire among those modern artists who represent this return of the cynicism. For this, we try to show to what extent the approximation of Baudelaire resulted, for Foucault, in his deviation from Sade.

Keywords: truth - cynicism - modernity - art 
CHAVES, E. "Corações a nu: coragem da verdade, arte moderna e cinismo em Baudelaire, segundo Foucault". In: Viso: Cadernos de estética aplicada, v. VI, n. 11 (janjun/2012), pp. 21-34.

DOI: $10.22409 / 1981-4062 / v 11 i / 117$

Aprovado: 17.05.2012. Publicado: 07.09.2012.

(C) 2012 Ernani Chaves. Esse documento é distribuído nos termos da licença Creative Commons Atribuição-NãoComercial 4.0 Internacional (CC-BY-NC), que permite, exceto para fins comerciais, copiar e redistribuir o material em qualquer formato ou meio, bem como remixá-lo, transformá-lo ou criar a partir dele, desde que seja dado o devido crédito e indicada a licença sob a qual ele foi originalmente publicado.

Licença: http://creativecommons.org/licenses/by-nc/4.0/deed.pt_BR

Accepted: 17.05.2012. Published: 07.09.2012.

(C) 2012 Ernani Chaves. This document is distributed under the terms of a Creative Commons Attribution-NonCommercial 4.0 International license (CC-BY-NC) which allows, except for commercial purposes, to copy and redistribute the material in any medium or format and to remix, transform, and build upon the material, provided the original work is properly cited and states its license.

License: http://creativecommons.org/licenses/by-nc/4.0/ 
"Antes de procurar o homem, deve-se achar a lanterna.

- Terá de ser a lanterna do cínico?"

Nietzsche, O Andarilho e sua sombra, 18

O último curso de Foucault no Collège de France, intitulado "A coragem da verdade", proferido no inverno de 1984, gira em torno de dois temas ou duas questões centrais: a do conceito grego de "parresia", ou seja, a do "franco falar", do "dizer verdadeiro" e, ao mesmo tempo, a da valorização do cinismo antigo como expressão máxima da "parresia". Se a questão da "parresia" não é nova, uma vez que já tinha sido mencionada em cursos anteriores, neste último curso ela aparece com uma conotação bem específica, qual seja, a de se localizar no interior das relações entre sujeito e verdade. Foucault parte da distinção entre uma "metafísica da alma" e uma "estilística da existência", a partir da análise de dois diálogos platônicos: o Alcebíades e o Laques. Constitui-se, desse modo, uma dualidade que, segundo ele, deixará marcas indeléveis em toda a história do pensamento ocidental. Assim, o "dar conta de si", objetivo maior da parrêsia socrática, personagem central nesses dois diálogos, pode ser entendido de duas maneiras, seja como a tarefa de ter de encontrar e de dizer o ser da alma (no Alcebíades), seja ainda como tarefa e trabalho que consiste em dar um estilo à existência (no Laques). ${ }^{1}$

Coube aos cínicos elevar à sua potência máxima a relação entre dizer verdadeiro e estilo de viver. "Escola" marginal, menor, em comparação com as outras "escolas" do chamado período helenístico, por não possuir uma doutrina sistemática, o cinismo deixou, na História da Filosofia, a marca do escândalo. Nele, a "coragem da verdade" se expressa num modo de viver que, semelhante ao dos cães, desconhece pátria, lar, abrigo permanente, muito menos o pudor ou ainda os benefícios de uma vida confortável. Vestido de trapos, mendigando, masturbando-se ou mesmo copulando em praça pública, o cínico não tem discípulos, não possui um lugar de destaque na Ágora: "O cinismo, ao longo de sua história, desde a época helenística até o início do cristianismo, foi, na paisagem da filosofia, do pensamento, da sociedade greco-romana, ao mesmo tempo muito familiar e inteiramente estranho. Foi comum, banal e inaceitável". ${ }^{2} \mathrm{O}$ destino do cinismo na História da Filosofia é bastante conhecido: transformado em três ou quatro anedotas, acabou se tornando o signo da má conduta, de uma insolência herética, que nada mais diz de verdadeiro. O cinismo e o cínico se transformaram em figuras absolutamente negativas.

Entretanto, Foucault irá mostrar que é possível encontrar em alguns momentos posteriores na história de nossa cultura uma espécie de ressurgência do cinismo antigo: no ascetismo cristão praticado por algumas ordens religiosas a partir da Idade Média (como os franciscanos, por exemplo), na figura do revolucionário dos séculos XVIII e XIX e, finalmente, no artista moderno, tal como ele se constitui no século XIX. Nessas três figuras, distantes e próximas ao mesmo tempo, o dizer verdadeiro, a insolência e um modo de vida incompatível com os padrões de suas épocas ainda se acoplam e 
constituem o que Foucault chamava de "estilística da existência". Interessa-nos aqui, especialmente, mostrar alguns aspectos da análise de Foucault em relação ao artista moderno, representado pela figura de Baudelaire.

As observações de Foucault acerca das relações entre cinismo e arte moderna ocupam a última parte da segunda hora da aula do dia 29 de fevereiro de 1984. Ele as chama, com cautela, de "anotações, de um trabalho possível"s, deixando de lado durante a aula uma longa passagem, que se encontra, entretanto, no manuscrito, na qual problematiza não apenas a relação entre arte moderna e práticas revolucionárias, mas também aquela entre cinismo, ceticismo e niilismo.

Entretanto, Foucault não deixa de assinalar que a relação entre arte e cinismo remonta aos gregos: "A sátira, a comédia, foram frequentemente atravessadas por temas cínicos e mais ainda elas constituíram, até certo ponto, um lugar privilegiado de expressão para temas cínicos". ${ }^{4}$ Além disso, na Europa medieval (Foucault se refere aqui aos conhecidos trabalhos de Bakhtin), a relação entre literatura e festa, literatura e carnaval, não deixa de ser uma espécie de manifestação da vida cínica: "a vida em estado nu, a vida violenta, a vida que escandalosamente manifesta a verdade". ${ }^{5}$ Mas, mesmo que consideremos estas duas experiências como modos de manifestação da vida cínica, nenhuma delas constituiu aquilo que a arte moderna constitui, de tal modo que nela, apenas nela, a questão do cinismo assume um contorno particularmente singular. Foucault justifica sua posição por duas razões: a primeira diz respeito à aparição de um tipo de vida absolutamente particular, peculiar e singular, o de uma "vida artista"; a segunda, por sua vez, diz respeito a uma concepção de arte, que não se caracteriza mais pela ornamentação ou pela imitação, "mas que é da ordem do desnudamento [mise à $n u$ ], do desmascaramento, de limpeza, de escavação, da redução violenta ao elementar da existência". ${ }^{6} \mathrm{Se}$, por um lado, não se pode desconhecer que tanto na Vida dos pintores, de Vassari, ou ainda na autobiografia de Benvenuto Cellini, já encontramos a circunscrição de uma "vida artista", o que distingue a ideia moderna de uma "vida artista" da ideia renascentista representada por Vassari e Benvenuto é justamente o fato de que, na ideia moderna, não poderia haver nenhuma exterioridade entre a vida do artista e a verdade da arte que sua obra expressa. Dessa maneira, a arte é capaz de engendrar uma forma de vida que vale como a "verdadeira vida", à custa de um rompimento com a vida ordinária, comum, do mesmo modo que a arte só pode ganhar raízes se for caucionada por uma vida, não uma vida qualquer, mas por uma "verdadeira vida". Trata-se, portanto, de uma "ruptura escandalosa" com a vida ordinária, comum, numa continuidade com o princípio cínico do viver escandalosamente. Anti-platonismo e anti-aristotelismo, dirá Foucault, ao mesmo tempo, como características da arte moderna: contra Platão, por conceder à arte o local por excelência de irrupção da verdade; contra Aristóteles, por sua vez, por recusar uma espécie de princípio de ordenamento, de ligação, entre a vida artista e uma regra previamente imposta, numa referência à crítica dos modernos a um possível caráter normativo da Poética. Desse modo, a relação da arte moderna com a cultura, com as normas sociais, com os valores 
e cânones estéticos, só poderia ser a da ordem da redução, da recusa e da agressão, constituindo assim uma função decididamente anticultural. Se a cultura pressupõe consenso e conciliação, a arte, com sua "coragem", torna possível a irrupção, em meio à cultura, de uma verdade bárbara. Verdade que não é nem exterior, nem acidental em relação à cultura: nessa medida, a arte se torna o próprio cinismo na cultura, como se o cinismo inerente às formas culturais se voltasse inteiramente contra estas. A arte é assim, aos olhos de Foucault, a instância privilegiada no mundo moderno para que o dizer verdadeiro se expresse. É no âmbito da arte, enfim, que poderíamos ainda reencontrar o gesto, a atitude cínica, essa "coragem de correr o risco de ferir". ${ }^{7}$

Qual é então o papel de Baudelaire neste enredo que reúne arte moderna e cinismo? Não podemos perder de vista que este é um momento no pensamento de Foucault em que ele se ocupa amiúde com Baudelaire. O curso $A$ coragem da verdade é contemporâneo das reflexões acerca do lluminismo, que vão constituir o texto "O que são as Luzes?",em cuja versão escrita para uma coletânea de textos de Foucault publicada em inglês Baudelaire assume um lugar especial e importante ${ }^{8}$, na medida em que se trata de uma referência francamente positiva, o que nem sempre foi o caso. Interessante neste aspecto é lembrar a referência a Baudelaire na época de Vigiar e punir. Aqui, a referência indica um distanciamento crítico, uma vez que Baudelaire é parte dos comprometidos com uma "reescrita estética do crime", o que implica a "apropriação da criminalidade sob formas aceitáveis". ${ }^{9}$ Na entrevista "Sobre a prisão", de 1975, ou seja, por ocasião das discussões que se sucederam à publicação de Vigiar e punir se pode encontrar no mesmo argumento a crítica a Baudelaire e a afirmação do caráter cínico da burguesia. Entendamos melhor isso: no interior da discussão acerca da conivência entre polícia e delinquentes, de tal modo que aquela se legitima por se apresentar como a que vai proteger e livrar a sociedade destes últimos, Foucault vai dizer que a posição de Baudelaire a respeito da burguesia é "ingênua" por imaginá-la "tola e pudica". Ao contrário, afirma Foucault, o lugar essencial da delinquência na nossa sociedade é resultado "da inteligência cínica do pensamento burguês do século XIX" - a burguesia, insiste Foucault, é "inteligente e cínica"10, "cínica" aqui no sentido pejorativo, moderno, da palavra. Em A vontade de saber, o primeiro volume da História da sexualidade, a partir da discussão crítica do que Foucault chamou de "hipótese repressiva", ele reafirmará este argumento ao dizer que a sociedade burguesa do século XIX "é uma sociedade de perversão explosiva e fragmentada" (p. 46), isto é, que ao invés de, pura e simplesmente, reforçar os mecanismos de repressão, incita à crescente proliferação de discursos sobre o sexo. Aqui estamos num registro bem distante daquele com o que nos ocupamos, uma vez que estamos diante de duas apreciações negativas: uma, em relação a Baudelaire e sua equivocada avaliação do modo como a burguesia exerce seu poder; outra, em relação ao próprio cinismo, também visto aqui na sua versão moderna, ou seja, como sendo algo de negativo, como um ardil - pois a burguesia é, ao mesmo tempo, "inteligente" e "cínica" - a serviço das relações de dominação. Ora, no último Foucault, tanto a relação com Baudelaire quanto com o cinismo mudou radicalmente. 
A referência a Baudelaire implica, além disso, a questão acerca das relações entre filosofia e literatura no pensamento de Foucault. Nesta perspectiva é importante retomar as análises de Roberto Machado em seu livro sobre este assunto. ${ }^{11}$ Machado mostra com rigor e precisão, no interior do pensamento de Foucault, os caminhos percorridos pela questão da literatura, o seu papel na formulação de ideias fundamentais na trajetória de Foucault. Assim sendo, o que acontece neste último momento na obra de Foucault "é o abandono do privilégio [da literatura], o desinteresse [da parte de Foucault] pela questão do ser da linguagem, o distanciamento da tese da intransitividade da escrita literária"12, que caracterizavam os textos do período arqueológico. Por outro lado, entretanto, Baudelaire, que havia sido raramente mencionado nos inúmeros artigos de Foucault acerca da literatura no período arqueológico, passa a ocupar um lugar de destaque no seu pensamento. O que não significa, pondera Roberto Machado, que se trate ainda de pensar a questão da literatura, mas, talvez, simplesmente de apenas ilustrar, com Baudelaire, a ideia de Modernidade mais como "atitude", como "gesto" do que a de uma época histórica precisa, como um complemento à análise do texto de Kant sobre a Aufklärung.

O estudo de Roberto Machado enfatiza a mudança do tom de Foucault, a partir de $A$ arqueologia do saber (1969), quando se trata da questão da literatura. Não por acaso o título do capítulo de seu livro que analisa o pensamento de Foucault a partir de 1969, tendo em vista esta questão, se chama "O ocaso da literatura". Com a ideia de "ocaso", Machado quer acentuar, entre outros, a perda do privilégio da literatura como "aspecto afirmativo de sua crítica [de Foucault] da estrutura antropológico-humanista da Modernidade"..$^{13}$ Esta mudança, a qual implica, por fim, em dizer que a literatura não se constitui, por si só, como efetiva resistência às relações de poder dominantes, pressupõe igualmente um tournant teórico, em especial em relação a Nietzsche, que de filósofo trágico ou ainda filósofo da linguagem por excelência se torna "um filósofo do poder ou das relações de poder". ${ }^{14}$

Entretanto, penso que no curso $A$ coragem da verdade a referência à arte moderna e a Baudelaire especificamente recoloca a questão das relações entre filosofia e literatura no pensamento de Foucault de outra maneira, a qual, por sua vez, só se torna inteligível no interior da questão do cinismo. Aqui, a literatura moderna não é mera ilustração de uma ideia; ao contrário, tal como a arte moderna em geral, ela se torna expressão altissonante e privilegiada da verdade. Trata-se ainda, certamente, de uma atitude, de um gesto, mas que se aparenta ao caráter transgressor da literatura que o Foucault do período arqueológico destacava, em especial no seu estudo sobre Bataille, de 1963. A relação com o cinismo recupera, em outros termos e por outras vias, o caráter transgressor da literatura e, por isso, a torna ao mesmo tempo inseparável da irrupção da verdade. Lembremos rapidamente que o sentido de transgressão para Bataille, tal como Foucault nos mostra no texto de 1963, se constitui em torno de cinco eixos fundamentais ${ }^{15}$ : 1) limite e transgressão formam um conjunto, uma relação de interdependência; 2) entre ambos acontece uma espécie de jogo, o qual se liga a duas 
formas de temporalidade, a do sagrado e a do profano; 3 ) o domínio da transgressão é, por excelência, o do erotismo, cujo sentido fundamental é religioso; 4) este sentido religioso, entretanto, não é o do cristianismo, que valorizou o trabalho em detrimento do gozo, mas o de uma religião primitiva, pré-cristã e 5) do ponto de vista teórico, as referências fundamentais de Bataille são Marcel Mauss e Roger Callois.$^{16}$ Diogo Sardinha assinala, por sua vez, que justamente "a experiência moderna da sexualidade, de Sade a Bataille, serve de ponto de partida para uma teoria da transgressão concebida sob o regime do excesso e da violência, teoria que desemboca no suplício do sujeito e na possibilidade da loucura". ${ }^{17}$

A literatura, neste quadro, é o modo essencial, o mais importante, de expressão do ultrapassamento dos limites, da possibilidade de realização deste desejo de excesso, daí decorrendo uma dupla transgressão, fundamental aos olhos de Foucault: uma, que se apresenta por meio de uma experiência com a linguagem e outra, intrinsecamente ligada à primeira, por uma experiência com o erotismo, a qual, justamente por ultrapassar os limites, exige e impõe outra linguagem. O exemplo privilegiado neste caso, tanto para Bataille como para Foucault, é o de Sade. ${ }^{18} \mathrm{~A}$ transgressão, desse modo, remete inteiramente ao campo do "humano, demasiado humano", isto é, ao da linguagem e ao do erotismo, os quais, na perspectiva de Foucault, só podem efetivamente ser formulados a partir da ideia nietzschiana da "morte de Deus": "Talvez a importância da sexualidade na nossa cultura, o fato de que desde Sade ela tenha sido tão frequentemente ligada às decisões mais profundas de nossa linguagem dizem respeito justamente a este vínculo que a liga à morte de deus". ${ }^{19}$ "Transgressão" é assim a expressão maior e constitutiva, por excelência, da própria ideia de humanidade, na contramão, por conseguinte, do humanismo da época moderna.

Ora, quando falamos de transgressão a partir desse último curso de Foucault já estamos num outro registro, num registro dominado pela preocupação com o nexo entre relações de poder, constituição da subjetividade e produção da verdade, um registro do qual a transgressão é muito mais um ato, um gesto, uma ação predominantemente política, que visa a opor-se, a resistir aos modos de exercício dominantes do poder. Permanece a ideia de transgressão pela linguagem, em especial pela linguagem erótica. Mas o que muda é justamente o fato de que Foucault já não privilegia mais Sade como uma espécie de modelo de transgressão, ele não nutre mais nenhuma grande admiração pelo "divino Marquês". Essa mudança, como se verá rapidamente em seguida, vai salientar o aspecto político que a concepção de transgressão assume explicitamente nos últimos textos de Foucault.

No importante texto "A vida dos homens infames" (1976), Sade aparece como uma espécie de modelo do infame inautêntico, o infame com glória, beneficiado pela fama, ao qual Foucault oporá os infames sem glória, aqueles a quem é negada a fala, aqueles a quem restará apenas o apagamento da própria voz e que devem ser, por conseguinte, banidos da memória coletiva. Ainda em 1976, na entrevista "Sade, sargento do sexo", ou 
seja, um pouco depois da publicação de Vigiar e punir e no mesmo diapasão de "A vida dos homens infames", ele dirá que não se deve sacralizar Sade e que este "formulou o erotismo próprio a uma sociedade disciplinar", isto é, "uma sociedade regulamentar, anatômica, hierarquizada, com seu tempo meticulosamente distribuído, seus espaços esquadrinhados, seus submissos e seus vigilantes" e, por isso, conclui ele, devemos sair tanto desta sociedade, quanto do "erotismo de Sade". ${ }^{20}$

O recurso a Baudelaire nos últimos textos de Foucault e em especial em $A$ coragem da verdade, faz-nos pensar que o poeta das Flores do mal é apresentado como uma espécie de antípoda do autor de Filosofia na alcova. E o que faz Foucault mudar de posição, ou seja, por que Baudelaire deixa de ser um ingênuo analista da condição de sua própria classe para se tornar um crítico ácido e mordaz dessa mesma classe? Tratase, repito, de uma mudança de avaliação motivada por uma mudança de perspectiva política. Voltemos ao final de "Sade, sargento do sexo". Foucault, como vimos, afirma que o erotismo de Sade também é uma expressão própria da sociedade disciplinar. Mas ele vai mais fundo, para mostrar que as implicações políticas da posição de Sade, coetâneas à sociedade disciplinar, reaparecem, altissonantes, em filmes como "Saló, os 120 dias de Sodoma" (1975), de Pasolini (citado explicitamente na entrevista) ou ainda, acrescentaríamos, em "O porteiro da noite", de Liliana Cavani, (1974):

O que me aborrece é que nos filmes recentes tem sido usado um certo número de elementos que ressuscitam, através do tema do nazismo, um erotismo do tipo disciplinar. Talvez tenha sido o de Sade. Tanto pior então para a sacralização literária de Sade, tanto pior para Sade: ele nos entedia, é um disciplinador, um sargento do sexo, um contador de bundas e de seus equivalentes. ${ }^{21}$

Ora, nesta perspectiva, é como se Baudelaire nos apresentasse a possibilidade de pensar uma relação entre linguagem e sexualidade, linguagem e erotismo, que pudesse escapar aos mecanismos disciplinares. E o que fundamenta esta diferença entre Baudelaire e Sade? Creio poder afirmar que esta diferença diz respeito ao papel destinado ao cinismo na análise de Foucault. Isto implicou um deslocamento da análise, que se retrai tanto da ênfase na questão do sadismo de Sade quanto na do seu estilo ou ainda na especificidade da ideia de razão, de lógica, que seu pensamento constituiria, além, é claro, das considerações acerca do seu estilo. Este deslocamento permite que Foucault se distancie criticamente tanto da obra "entediante", "sacralizada", de Sade, uma vez que nesta o tema do sexo ainda não se desprendeu inteiramente dos procedimentos disciplinares, quanto da patologização das condutas e da afirmação da sexualidade como uma espécie de "causa universal" de todas as doenças, de todos os desvios, que ultrapassa o indivíduo e alcança a vida social, ou ainda, como ele dirá posteriormente em $A$ vontade de saber, a vida da "população". Este processo de patologização do cotidiano em nome da normalização das condutas constitui, nas análises de Foucault, a partir do curso O poder psiquiátrico (1973-1974), o triunfo total da psiquiatria no século XIX, sua legitimidade para além dos muros do asilo, uma legitimidade de ordem muito mais política do que propriamente epistemológica, uma vez 
que nesse processo se aliam estratégias de prevenção, tratamento, cura e observação contínua e metódica, controle e vigilância permanente dos pequenos gestos, hábitos e atitudes. Como expressão dos procedimentos disciplinares, o sexo em Sade não poderia, portanto, se constituir como resistência a esses mecanismos de normalização. A sua "sacralização literária" (de Bataille a Blanchot, de Klossowski a Barthes) teria nos impedido de ver isso claramente.

Não esqueçamos ainda que em 1976, por ocasião dessa entrevista sobre Sade, Foucault está concluindo o primeiro volume da História da sexualidade. Aqui, Sade também é visto a partir de uma distância crítica. Esta distância se expressa em pelo menos dois aspectos importantes e fundamentais. No primeiro, a literatura "escandalosa" do século XVIII estaria em continuidade com a "colocação do sexo em discurso", que tem suas raízes numa "tradição ascética e monástica" que vem de longo tempo e que a pastoral do século XVII tornara "uma regra para todos". Nesta perspectiva, Sade, ao exigir das narrativas em Os 120 dias de Sodoma "o maior e mais extenso detalhamento", que "não se disfarce nenhuma circunstância" e não se escondam mesmo as "menores circunstâncias", retoma as mesmas disposições preconizadas pelos "diretores espirituais" e seus termos "parecem transcritos dos tratados de direção espiritual". ${ }^{22}$ No segundo, Sade é considerado como um contemporâneo dos primeiros eugenistas, como peça fundamental no momento de passagem da "consaguinidade" (ou de uma "simbólica do sangue"), quando o poder fala pelo sangue, para a "sexualidade" tornada objeto de uma "analítica", de um esquadrinhamento disciplinador, ritualístico e contínuo. Mesmo que em Sade o sexo já seja "sem norma", já não possua uma "regra intrínseca" formulada a partir de uma pretensa "natureza própria" - era mais ou menos isso que Foucault elogiava nos textos da "arqueologia" - ele sucumbe, por outro lado, à "lei ilimitada" de um poder igualmente ilimitado, um poder que "só conhece sua própria lei", poder de vida e morte próprio ao exercício da soberania, de uma "soberania única e nua". Em outras palavras, de um poder coetâneo ao exercício de um "direito ilimitado da monstruosidade onipotente" de tal modo que "o sangue absorveu o sexo" ${ }^{23}$, ou seja, o poder de soberania absorveu o bio-poder. ${ }^{24}$

Se, além disso, levarmos em atenta consideração a crítica aos desdobramentos da posição de Sade e sua vinculação a uma interpretação do nazismo como um sadismo, tal como exposta em alguns filmes, comparando-a com a perspectiva adotada em $A$ vontade de saber, podemos perceber o quanto esta responde e complementa aquela. $\dot{E}$ como se Foucault nos dissesse que, de fato, um filme como "Saló" aponta um problema, uma questão relevante, mas que a solução proposta por Pasolini não the parece satisfatória, uma vez que o fascismo é representado no filme como uma espécie de derivação pervertida das ideias de Sade. Mas, nem por isso, acrescenta ele, menos tediosa. A posição de Foucault é diferente. Comprometido com o modo de exercício do poder próprio à soberania, não é por acaso que Sade será invocado e emprestará seu nome para que duas combinações absolutamente terríveis entre a simbólica do sangue e a analítica da sexualidade possam surgir: o racismo moderno, isto é, o racismo biológico, 
e o nazismo. ${ }^{25}$ Assim, não são nem o nazismo, nem o racismo, que uma vez constituídos, podem invocar Sade para legitimar suas práticas ditas sádicas. Ao contrário, é a posição de Sade, no limiar entre uma "simbólica do sangue" e uma "analítica da sexualidade", que torna possível a invocação de seu nome em diversas interpretações do nazismo, como uma conjugação entre loucura e sexo.

O distanciamento crítico em relação a Sade se radicaliza por ocasião do elogio de Foucault à "subcultura" sadomasoquista que ele encontrou na Califórnia. Para justificar isso, refiro-me a uma entrevista de agosto de 1984, na qual este elogio parte de um princípio inteiramente oposto à perspectiva que Foucault julga encontrar em Sade, qual seja, em vez do vínculo intrínseco entre prazer e sexo (que Sade herda de uma longa tradição iniciada pelos gregos), a separação entre prazer e sexo, uma separação necessária para que se possa subverter, transgredir, os limites estreitos da nossa compreensão dos prazeres. A cena $S / M$ da Califórnia é uma cultura, ou melhor, uma subcultura, não no sentido de uma cultura inferior, é claro, mas de uma cultura outra, diferente, alternativa, que, por seu caráter transgressor, é subterrânea, oculta, obscurecida por sua redução ao patológico. Como tal, não está comprometida, como em geral nos faz crer uma percepção mais imediata e ingênua, com a tortura, o sofrimento e a morte, mas sim com o prazer, mesmo que sua obtenção transgrida todos os códigos instituídos. Nesta perspectiva, como toda subcultura, esta cena se define melhor por seu comprometimento com a ideia de criação, de "invenção" de novas formas de prazer, do que pela associação aos rituais de sofrimento, dor e morte, mediados pela figura do senhor e do escravo, que constituem o estereótipo do sadomasoquismo: "A ideia que S/ $M$ está ligado a uma violência profunda, que sua prática é um meio de liberar esta violência, de dar livre curso à agressão é uma ideia estúpida" ${ }^{26}$ Eis, portanto, a primeira grande consequência que se pode tirar da relação entre o cinismo e a arte moderna: a despatologização das condutas sexuais escandalosas, o comportamento sexual transgressor como modo de vida, como experiência com os limites do próprio corpo e não como sintoma de um distúrbio mental ou de uma perversão. Ou seja, tudo aquilo que o nazismo quis apagar e destruir com as sucessivas exposições intituladas "Arte degenerada".

Colocar em contraste as interpretações distintas que Foucault fez, ao longo de sua obra, de Sade (que passa do elogio à crítica) e Baudelaire (que faz o caminho contrário), mostra também, com clareza, o quanto ele procura se distanciar de pelo menos duas interpretações de Baudelaire que permearam a sua própria formação filosófica, as de Sartre e Bataille. Decididamente, o Baudelaire do último Foucault nada tem em comum com o Baudelaire de Bataille, tal como este o apresenta seja, por exemplo, em $A$ literatura e o mal, ou ainda em O erotismo, ambos publicados em 1957. Em ambos estes textos, Baudelaire é interpretado a partir da relação com o Mal. Tal como o título de $A$ literatura e o mal já anunciava, Bataille concebe a literatura como a expressão por excelência de "uma forma aguda do Mal", o que não quer dizer, como ele mesmo o reitera, uma ausência de moral; ao contrário, trata-se de uma posição que exige mais 
que uma moral, ou seja, uma "hipermoral". ${ }^{27}$ É neste diapasão, ou seja, o das relações entre a literatura e o mal, cujo ponto de partida é um intenso e provocador diálogo com a interpretação que Sartre fizera de Baudelaire dez anos antes, ${ }^{28}$ que o autor de $O$ pintor da vida moderna será analisado por Bataille neste livro. Em O erotismo, por sua vez, a interpretação de Bataille retoma a relação com o Mal, em especial a partir de um texto de "Projeteis", no qual Baudelaire afirma que "a suprema volúpia do amor está em saber que se faz mal". ${ }^{29}$ Ora, em uma entrevista de 1984, Foucault definirá a tarefa da filosofia para além do problema do "mal": "O trabalho do pensamento não é de denunciar o mal que habitaria secretamente tudo o que existe, mas de pressentir o perigo que ameaça tudo o que é habitual e de tornar problemático tudo o que é sólido". ${ }^{30}$ Em outra entrevista de 1984, na qual ressoa a interpretação que Sartre fez de Baudelaire e, por conseguinte, a aproximação, pelo menos neste aspecto, de Bataille em relação a Sartre, Foucault questiona a afirmação do autor de $O$ ser e o nada de que "o poder é o mal", o "mal supremo". ${ }^{31} \mathrm{Em}$ duas outras entrevistas, realizadas por Dreyfus e Rabinow em Berkeley, das quais possuímos uma versão inglesa (de 1983) e outra, francesa (de 1984, publicada como anexo da edição francesa do conhecido livro de Dreyfus e Rabinow sobre Foucault), Foucault volta a se contrapor a Sartre, mostrando em que consiste a diferença de sua posição, uma vez que se podia atribuir a ambos, a ele e a Sartre, uma mesma ideia, qual seja, a de que o homem "cria a si mesmo": na versão inglesa, citando as análises sartrianas de Baudelaire e Flaubert, embora considere acertada a ligação entre "trabalho criador e relação a si" feita por Sartre, Foucault critica a relação estabelecida com a moral da autenticidade, insistindo na ideia de que o importante é exatamente o inverso, ou seja, o de ligar a relação a si ao trabalho criador $^{32}$; na versão francesa, "corrigida e modificada" por Foucault, dizem Dreyfus e Rabinow, ele mantém sua crítica à moral sartriana da autenticidade sem, entretanto, citar as análises sobre Baudelaire e Flaubert. ${ }^{33}$

Mas é recorrendo ao próprio Baudelaire que podemos encontrar a justificativa maior para a relação feita por Foucault entre ele e o cinismo, uma vez que esta figura - a do cínico também interessou sobremaneira a Baudelaire. Basta para isso lembrar dois dos seus "Pequenos poemas em prosa". No primeiro, denominado de "A moeda falsa", ressoa o episódio da vida de Diógenes de Sinope, fartamente retomado pela posteridade e que se tornou um tema comum a filósofos e escritores. ${ }^{34}$ No segundo, "Os bons cães", reencontramos não apenas o animal preferido dos cínicos, mas também uma descrição dos "bons cães", aqueles que surgem por invocação da "musa familiar", por oposição aos "maus cães", ligados à "musa acadêmica", na qual a figura do cínico aparece como pano-de-fundo: "Invoco a musa familiar, a citadina, a viva, para que ela me ajude a cantar os bons cães, os infelizes cães, os cães emporcalhados, aqueles que todos evitam, por empestados e piolhentos, salvo o pobre, de quem são parceiros, e o poeta, que os fita com um olhar fraterno". ${ }^{35}$ Assim, os bons cães, os pobres e o poeta convivem no mesmo canil "sedoso e fofo" e os "cães", alegoria dos pobres, dos miseráveis, dos que vivem, como os trapeiros, cobertos de farrapos e entre farrapos, são o motivo do canto do poeta: "Eu canto o cão enlameado, o cão pobre, o cão sem domicílio, o cão 
vagabundo, o cão cujo instinto como o do mendigo, do boêmio e do histrião, é maravilhosamente espicaçado pela necessidade, essa tão boa mãe, essa verdadeira padroeira das inteligências!". E são esses cães solitários, desgraçados, errantes, que "vivem nos barrancos sinuosos das cidades imensas", que com os olhos "pestanejantes e espirituais" se dirigem a um homem abandonado, dizendo: "Leva-me contigo, e das nossas duas misérias talvez tenhamos a fazer uma espécie de felicidade!".

\section{* Ernani Chaves é professor associado do Departamento de Filosofia da UFPA.}

${ }^{1}$ FOUCAULT, M. La courage de la verité. Paris: Gallimard/Seuil, 2009, p. 149. Doravante citado como CV, seguido do número da página. Ver, a respeito, ORTEGA, F. Amizade e estética da existência em Michel Foucault. Rio de Janeiro: Graal, 1999, cap. 6.

${ }^{2}$ CV, p. 213. Já no curso "A Hermenêutica do Sujeito", de dois anos antes, Foucault afirmava que o "personagem cínico" era, ao mesmo tempo, o "ponto extremo" e o "modelo negativo" da filosofia ( $p$. 190).

${ }^{3} \mathrm{CV}$, p. 174.

${ }^{4}$ CV, p. 172.

${ }^{5}$ Idem.

${ }^{6} \mathrm{CV}$, p. 173.

${ }^{7}$ CV, p. 174.

${ }^{8}$ Esta primeira versão foi publicada em 1984, em inglês, em uma coletânea de textos de Foucault organizada por Paul Rabinow (The Foucault Reader. New York: Pantheon Books, 1984). No número de maio de 1984 do Magazine littéraire, um mês antes de sua morte, Foucault publica uma segunda versão, mais curta e que suprime a referência a Baudelaire. Exclusivamente sobre este escrito de Foucault, ver o comentário de DEKENS, O. Qu'est-ce que les Lumières?, de Foucault. Rosny: Bréal, 2004.

${ }^{9}$ FOUCAULT, M. Vigiar e punir. Petrópolis: Vozes, 1977, p. 61.

${ }^{10}$ FOUCAULT, M. "Sobre a prisão". In: Microfísica do poder. Rio de Janeiro: Graal, 1979, p. 137.

${ }^{11}$ MACHADO, R. Foucault, a filosofia e a literatura. Rio de Janeiro: Jorge Zahar, 2000.

${ }^{12}$ Ibidem, p. 125

${ }^{13}$ Ibidem, p. 116.

${ }^{14}$ Inidem, p. 123. Nesta afirmação ressoa uma afirmação do próprio Foucault na entrevista "Sobre a prisão", já referida: "Nietzsche é aquele que ofereceu como alvo essencial, digamos ao discurso filosófico, a relação de poder [...] Nietzsche é o filósofo do poder, mas que chegou a pensar o poder sem se fechar no interior de uma teoria política" (p.143).

${ }^{15}$ Cf. MACHADO, R. Op. cit., pp. 59-64.

${ }^{16} \mathrm{Em} O$ erotismo, Bataille assinala que Callois, discípulo de Mauss, com sua "teoria da festa", afirmou o caráter sagrado da transgressão (Porto Alegre: LPM, 1987, p. 43).

17 SARDINHA, D. "As duas ontologias críticas de Foucault: da transgressão à ética". In: Trans/Form/Ação, v. 32, 2010, p. 189. 
${ }^{18}$ Sobre Foucault e Sade, cf. CHARLES, S. "Foucault leitor de Sade: da infinitude do discurso à finitude do prazer". In: Aurora: Revista de Filosofia, v. 19, n. 25 (jul/dez, 2007). Segundo Charles, a presença de Sade no período da arqueologia "é bem diferenciada e ela é indissociável das leituras que Foucault faz na época de Blanchot ou de Bataille, que unem o pensamento de Sade à questão essencial da transgressão" (pp. 335-336). Charles distingue, com razão, este primeiro Sade em Foucault de um segundo, no período que vai de As palavras e as c(1966) até o $1^{\circ}$ volume da História da sexualidade (1976). Aqui, "a leitura foucaultiana vai se mostrar cada vez mais crítica em relação a Sade" (p. 346).

${ }^{19}$ FOUCAULT, M. Dits et écrits, v. I. Paris: Gallimard, 1994, p. 235.

${ }^{20}$ FOUCAULT, M. Dits et écrits, v. II. Paris: Gallimard, 1994, p. 821.

${ }^{21}$ Ibidem.

${ }^{22}$ FOUCAULT, M. História da sexualidade I: A vontade de saber, Rio de Janeiro: Graal, 1977, p. 24.

${ }^{23}$ Ibidem, p. 139.

${ }^{24}$ Para uma leitura crítica da interpretação de Foucault, cf. ROBERT MORAES, E. "A imaginação no poder". In: Lições de Sade. Ensaios sobre a imaginação libertina. São Paulo: lluminuras, 2006.

${ }^{25}$ Na última aula, de 17 de março de 1976, do curso "Em defesa da sociedade", Foucault escreve, neste mesmo diapasão: "vocês compreendem então, nessas condições, porque os Estados mais assassinos são, ao mesmo tempo, forçosamente os mais racistas" (p. 308).

${ }^{26}$ FOUCAULT, M. Dits et écrits, v. IV. Paris: Gallimard/Seuil, p. 737. É muito provável que a releitura que Foucault fez do sadismo e do masoquismo tenha sido também o resultado de sua leitura do livro de Deleuze sobre o assunto (Sacher Masoch: o frio e o cruel. Rio de Janeiro: Jorge Zahar, 2009), que havia sido publicado em 1967 e que vai inteiramente na contramão da "sacralização literária" de Sade, criticada por Foucault. Agradeço a Cíntia Vieira da Silva, que me lembrou dessa confluência.

${ }^{27}$ BATAILLE, G. La Literatura y el Mal. Ediciones elaleph.com, 2000, p. 23.

${ }^{28}$ SARTRE, J.-P. Baudelaire. Paris: Gallimard, 1947. Ainda sobre o Baudelaire de Sartre, ver BLANCHOT, M. "L'échec de Baudelaire". In: La part du feu. Paris: Gallimard, 1949.

${ }^{29}$ BATAILLE, G. Op. cit., p. 83 e ss. Bataille retoma a frase de Baudelaire mais uma vez neste mesmo contexto (p. 91). Para o texto de Baudelaire, cf. Charles Baudelaire, Poesia e prosa. Rio de Janeiro: Nova Aguillar, 2002, p. 505.

${ }^{30}$ FOUCAULT, M. Dits et écrits, v. IV. Op. cit., p. 612.

${ }^{31}$ Ibidem, p. 728. Certamente Foucault chegou a esta conclusão a partir dos trechos fundamentais do Baudelaire, de Sartre, acerca do Mal, ou melhor, das relações entre Bem e Mal, que culminam na relação entre poesia e Mal. Quando a poesia, diz Sartre, toma o mal como objeto, "as duas espécies de criação [a do Bem e a do Mal - EC], tendo em vista a responsabilidade limitada, se reúnem e se fundam, nós possuímos desta feita, uma flor do mal" (pp. 68-69). Ver ainda a respeito SABOT, P. "Lectures de Baudelaire: Benjamin, Sartre, Foucault". In: L'École de Philosophes, n. 10 (déc/ 2008). Para Sabot, o Baudelaire de Sartre "constitui, de qualquer modo, um anexo de O ser e o nada" (p. 12). Sartre também continua suas reflexões sobre a literatura e o mal no livro sobre Jean Genet (Saint Genet, ator e mártir, de 1952). Ver, a respeito, BLANCHOT, M. "Où va la littérature?". In: Le livre a venir. Paris: Gallimard, 1959, p. 313.

${ }^{32}$ FOUCAULT, M. Dits et écrits, v. IV. Op. cit., pp. 392-393.

${ }^{33}$ Ibidem, p. 617.

${ }^{34}$ BAUDELAIRE, C. Op. cit., pp. 312-313.

${ }^{35}$ Ibidem, p. 339. 